\title{
LA POLITIICA FERROVIARIA EN ESPAÑA. BALANCE DE SU PLANIFICACIÓN Y EJECUCIÓN DE LOS ÚLTIMOS TREINTAAÑOS
}

\author{
Josefina Cruz Villalón \\ Departamento de Geografía Humana. Universidad de Sevilla \\ jcvillalon@us.es
}

“Esta opinión en honrada:

Procure siempre acertalla

El honrado y principal

Pero si la acierta mal

Defendella y no enmedalla"

(Guillén de Castro. Las mocedades del Cid)

\begin{abstract}
"Le Marquis cherchant à rentrer dans la vie politique, préparait de longue main sa candidature á la Chambre des députés. Il faisait, l’hiver, des nombreuses distributions de fagors, et, au Conseil géneral, réclamait avec exaltation toujours des routes par son arrondissement"

(Flaubert, Madame Bovary)
\end{abstract}

\section{RESUMEN}

En este artículo se realiza un recorrido por los documentos de planificación general de las infraestructuras ferroviarias en España desde 1987 hasta hoy. El objetivo es valorar el alcance de tal planificación y su efectiva ejecución a lo largo de los últimos treinta años, bajo dos ideas centrales: la importancia creciente de la planificación, en términos generales, como instrumento de la acción de gobierno y su control externo; y su especificidad en el caso de las infraestructuras del transporte, por el largo periodo de maduración y ejecución; impactos económicos y ambientales; e impronta y perdurabilidad en el territorio.

Fecha de recepción: noviembre 2015.

Fecha de aceptación: enero 2017. 
Palabras clave: Planificación de infraestructuras del transporte, planificación de infraestructuras ferroviarias en España, Alta Velocidad.

\section{ABSTRACT}

In this article we analyse railway transport planning in Spain from 1987 to the present day. The aim is to evaluate the extent of this planning and its implementation over the last 30 years. We focus on two main ideas: the increasing weight of planning as a tool for government activity and its external control, in general; and the time spent on planning and implementation; economic and environmental effects; and the impact on territory, in the case of transport infraestructures

Keywords: Infraestructure Planning, Railway Transport Planning in Spain, High-speed Train.

\section{INTRODUCCIÓN}

La planificación parece estar consolidada como una de las principales vías de intervención pública en múltiples ámbitos de actividad en los distintos niveles de la Administración. Es un mecanismo de ordenación técnica de su propia acción en las áreas en las que tiene competencia; es una propuesta y compromiso político con la sociedad para alcanzar unos determinados objetivos, que debe ser contrastados en el horizonte temporal que se haya marcado; pretende ser, cada vez en mayor medida por imperativo legal, un proceso de interacción entre la propuesta político-técnica inicial y el debate con distintos agentes sociales y económicos para alcanzar una acción de gobierno consensuada, en la que criterios técnicos y políticos sean contrastados con la sociedad que ha de valorar los beneficios y costes de la acción pública en su desarrollo económico y social. Por todo ello, la planificación ha adquirido una gran presencia en la acción de gobierno a distintas escalas, se han desarrollado técnicas de planificación más precisas y la sociedad es cada vez más exigentes sobre el control de las acciones que se proponen desarrollar.

En el caso de las infraestructuras de transporte, su planificación alcanza particular relieve por distintas circunstancias, entre las que han de ser destacadas el elevado coste económico, los impactos económicos, sociales y ambientales que su ejecución y puesta en servicio comportan, así como la impronta y perdurabilidad que en el territorio tiene su implantación. Como es sabido, desde la toma de la decisión a la puesta en servicio de una nueva infraestructura de transporte se requiere un periodo de tiempo cada vez más largo: desde la fase de planificación, estudios previos, la concertación con otras Administraciones y con la ciudadanía, la evaluación ambiental, la elaboración de los anteproyectos y el proyecto constructivo final y sus correspondientes fases de información pública, y la decisión de ejecutar la infraestructura con el consiguiente proceso de concurso público, decisión que puede estar sustentada en razones técnicas, políticas (en relación a las prioridades que se establecen) y económicas (disponibilidad presupuestaria y/o financiera), sin entrar en las incidencias presupuestarias y técnicas que se producen durante el periodo de ejecución. Todo ello repercute en la prolongación en el tiempo de la entrada en servicio de una infraestructura largamente reclamada o prometida. 
Pero sobre todo hay que insistir en la irreversibilidad que tienen muchas de las decisiones en materia de infraestructuras del transporte. En parte, está relacionado con cuanto acabamos de exponer sobre el largo proceso de maduración y ejecución de una infraestructura, y excepcionales son los casos en los que hay vuelta atrás en una decisión de estas características y se llegue a la resolución de abandonar su construcción. En parte también se han tomado decisiones cuyo alcance no fue suficientemente sopesado en su momento o han generado una dinámica que lleva a forzar el rumbo inicialmente previsto. En este sentido cobra particular relevancia la planificación y la toma de decisiones previas a la ejecución de las infraestructuras del transporte.

Nuestro objetivo es aplicar este planteamiento a las infraestructuras del transporte ferroviario en España. No es fácil establecer un punto de partida para la realización de tal análisis precisamente por cuanto acabamos de mencionar, salvo que retrotraigamos el punto de partida al momento de la construcción de las primeras líneas en España, mediado el siglo XIX, a la decisión de construir la red ferroviaria española en un determinado ancho de vía (Moreno Fernández, 1999) o a los términos en los que se realizaron las concesiones a empresas privadas de trayectos ferroviarios (Gómez Mendoza, 1989). Siendo consciente de que no hay balance sin antecedentes, hemos optado por realizarlo a partir de Plan de Transporte Ferroviario de 1987, al que han sucedido otros planes ferroviarios o de transportes en general. Se dispone en estos momentos, treinta años después, de una perspectiva suficiente para conocer y valorar el alcance de tal planificación, las aportaciones de los sucesivos planes, desviaciones del modelo si lo hubiera, o sustitución por otros modelos si fuera el caso.

\section{EL PLAN DE TRANSPORTE FERROVIARIO DE 1987 (PTF1987)}

El PTF1987 es la respuesta del Gobierno de España a las reiteradas críticas que se venían produciendo por el cierre de cerca de 1.000 kilómetros de líneas ferroviarias dos años antes, debido a su obsolescencia y a la pérdida de competitividad del conjunto de la red ferroviaria en relación a la carretera, tanto en transporte de viajeros como de mercancía, de modo que año tras año el ferrocarril venía perdiendo cuota en el transporte terrestre (Muñoz Rubio, 1984; Serrano et al., 2010). Ello no fue sino el resultado de una clara apuesta por las inversiones en carretera, la industria del automóvil y el vehículo privado, mientras que en paralelo se reducía la inversión pública en la red ferroviaria, nacionalizada en 1941. El sistema ferroviario y sus fases expansivas o de contracción deben ser explicados como una variante dependiente de las políticas económicas (Muñoz Rubio, 1984) que se implantan en cada periodo y no solo como producto de esa específica política sectorial. Hoy quizás habría que añadir, al argumento de Muñoz Rubio de 1984, la importancia de las políticas ambientales de la UE en su apuesta por el transporte público frente al privado y por el transporte ferroviario menos contaminante que la carretera (Libro Blanco, 2011).

El PTF1987 se presenta como un plan global a medio-largo plazo, extendiéndose sus actuaciones hasta el año 2000, con un volumen total de inversiones de 2,1 billones de pesetas. El objetivo fundamental es la reversión del estancamiento del ferrocarril (Izquierdo et al. 1999) y la recuperación de su competitividad como modo de transporte terrestre, en base al incremento de la velocidad de los trenes, a partir de la acometida de distintas actuaciones en electrificación, acondicionamientos, desdoblamiento de algunos tramos y la construcción de 
nuevas variantes en determinados trayectos. Con este conjunto de actuaciones se pretendía elevar la velocidad media de los trenes a $200 \mathrm{~km} / \mathrm{h}$ en $2.300 \mathrm{~km}$ de la red para el año 2000 (de los cuales hasta $250 \mathrm{~km} / \mathrm{h}$ en el trayecto Madrid-Sevilla) y a $160 \mathrm{~km} / \mathrm{h}$ en distintos tramos de enlace de la red.

La propuesta del PTF1987 identifica un eje vertebrador central noreste-suroeste, desde Barcelona a Sevilla (Figura $\mathrm{n}^{\circ}$ 1). El sector norte de este eje central (Madrid-Barcelona) constituye la charnela de dos bucles: uno de ellos, que denominaremos bucle mediterráneo, cierra la comunicación entre Madrid - Valencia - costa mediterránea - Tarragona - Barcelona -Zaragoza - Madrid; y el otro, el bucle castellano-vasco, entre Madrid - Valladolid (con un nuevo túnel de $10 \mathrm{~km}$ ) - Palencia (con un ramal hacia León)- País Vasco - Navarra Zaragoza -Madrid. En el conjunto de estos trayectos se circularía a $200 \mathrm{~km} / \mathrm{h}$, salvo algunos tramos en Navarra y el País Vasco que se reduciría $160 \mathrm{~km} / \mathrm{h}$. La tercera prioridad establecida en el PTF1987 es la conexión con Portugal, también a $160 \mathrm{~km} / \mathrm{h}$, que se dibuja a partir del eje vertebrador central a la altura de Ciudad Real enlazando con Badajoz, y se presume que con Lisboa. Esta red principal se refuerza con algunos tramos (marcados en azul en la figura $\mathrm{n}^{\circ} 1$ ) de conexión con el resto de la red: hacia Galicia desde León, y hacia la frontera francesa en Cataluña, y otros enlaces o prolongaciones, de más difícil explicación desde la perspectiva de su aportación a la estructura del sistema ferroviario. El objetivo en estos trayectos es el de elevar también la circulación a $160 \mathrm{~km} / \mathrm{h}$ mediante actuaciones de electrificación y/o renovación de las vías. El PTF1987 trataba, pues, de integrar tanto la mejora y renovación de la red existente, o la construcción de nuevos trazados, con la finalidad de mejorar la calidad de los servicios y reducir los tiempos de viaje, como dar cobertura a los gastos de explotación y reducir el déficit de RENFE (Villaronte Martinez, 1999: 162).

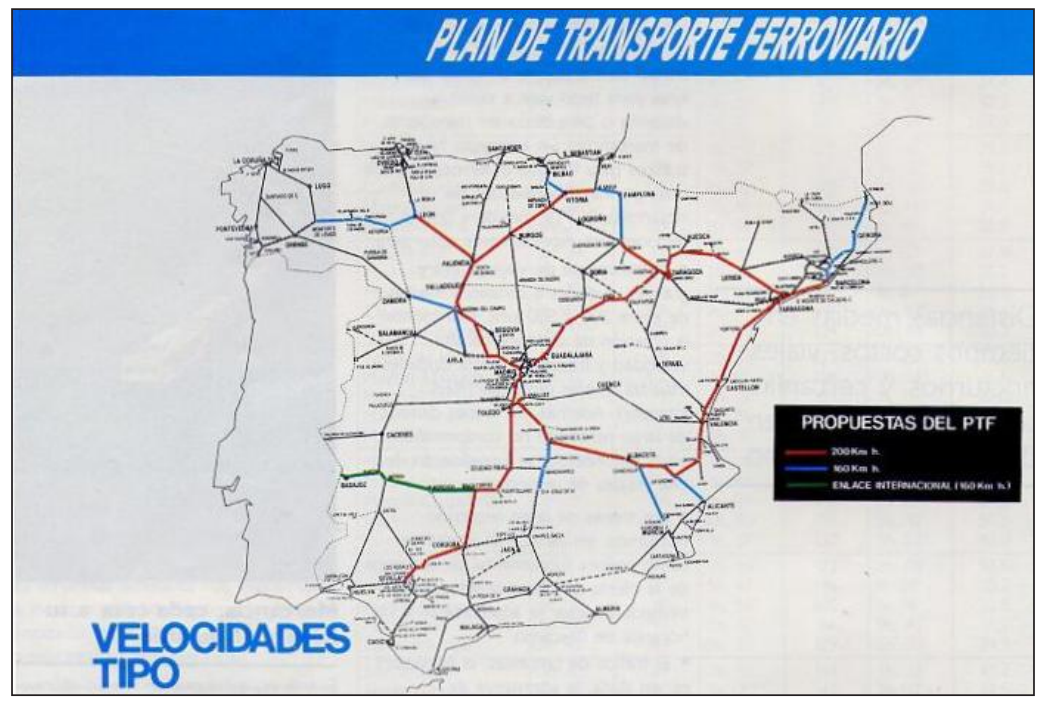

Fuente: Ferropedia http://ferropedia.es/wiki/Plan_de_Transporte_Ferroviario_\%281987\%29 
Entre las variantes previstas (Guadarrama, Vitoria-Bilbao, ...) se encontraba un nuevo acceso a Andalucía, a través de Brazatortas, por el estrangulamiento que suponía el paso por Despeñaperros para las relaciones con el sur de la península. Pero pronto el entonces denominado Nuevo Acceso Ferroviario a Andalucia (NAFA) adquiriría todo el protagonismo: por el volumen de inversiones que captó, por la prioridad en su ejecución frente al trayecto Madrid-Barcelona y por la decisión que se toma en el Consejo de Ministros del 9 de diciembre de 1988 de construir todo el eje vertebrador central desde Barcelona a Sevilla, no solo Madrid-Sevilla, en ancho UIC o estándar. La decisión de adoptar el ancho UIC en esta nueva línea "hizo saltar por los aires" la coherencia del PTF1987 (Aparicio, 2010: 14).

Un año antes, en los debates en torno a la aprobación del PTF1987, los responsables del Ministerio y el propio Ministro en comparecencias parlamentarias explicaban la decisión de no introducir el ancho UIC en la red ferroviaria española: el coste económico de la operación y las dificultades técnicas para su materialización constituían la base de su argumentación. Sin embargo, en octubre de 1988 el Gobierno encarga a RENFE el estudio del cambio de ancho, poco después ( 9 de diciembre) se toma en Consejo de Ministros el acuerdo ya mencionado, y en el propio mes de diciembre (Consejo de Ministros del 23 de diciembre) se acuerda también la adquisición del material móvil en ancho UIC, con el objetivo de que pudieran entrar en servicio en la primavera de 1992 para la inauguración de la Exposición Universal de Sevilla.

Sin entrar a considerar el valor que el Gobierno da a su propio plan de infraestructuras ferroviarias, aprobado tan solo 20 meses antes, y cómo se incorpora una decisión al margen del Plan, resulta difícil pensar que los estudios técnicos realizados en ese breve periodo de tiempo pudieran abordar con la necesaria profundidad las repercusiones de toda índole que tal decisión entrañaba. Pero la decisión fue tomada y durante un corto periodo de tiempo se mantuvo que la extensión el ancho UIC al conjunto de la red, o al menos a las líneas vertebradoras del PTF1987 $(7.000 \mathrm{~km})$ se alcanzaría en el horizonte del Plan: año 2000. Poco después (1989-1990) la evidencia de un coste económico inasumible y las dificultades técnicas de su materialización llevaron a acotar la extensión del ancho UIC al eje vertebrador Sevilla-Madrid-Barcelona-Frontera Francesa, y su implantación posterior en las nuevas líneas hacia el País Vasco y la conexión con Portugal. Así, el eje vertebrador central queda en una paradójica situación de aislamiento del conjunto de la red ferroviaria española y se asiste desde entonces al desarrollo de técnicas de compatibiliad (traviesas polivalentes, cambiadores de ancho, tercer carril, trenes de rodadura desplazable) entre el ancho ibérico o ancho RENFE $(1.668 \mathrm{~mm})$ y el ancho UIC $(1.435 \mathrm{~mm})$ para darle la mayor coherencia posible a esta decisión ya irreversible.

\section{EL PLAN DIRECTOR DE INFRAESTRUCTURAS 1993-2007 (PDI1993) Y EL PLAN DE INFRAESTRUCTURAS FERROVIARIAS 1995-2000 (PIF1995)}

Siete años más tarde, en el Consejo de Ministros de 4 de marzo de 1994, el Gobierno aprueba el Plan Director de Infraestructuras 1993-2007, luego refrendado en el Congreso de los Diputados en sesión plenaria de 21 de diciembre de 1995. En desarrollo del mismo, en marzo de 1996, la Dirección General de Infraestructuras del Transporte Ferroviario aprueba el Plan de Infraestructuras Ferroviarias 1995-2000, con el objetivo de definir con mayor 
precisión, tanto desde el punto de vista técnico como presupuestario, las actuaciones previstas en el PDI1993, y para establecer las prioridades de realización tomándose asimismo en consideración distintos escenarios presupuestarios.

El PDI1993 es el primer plan de carácter estratégico elaborado en España para el conjunto de las infraestructuras de competencia estatal, en el que se incluyen no solo los distintos modos de transporte (carreteras, ferrocarriles, puertos y aeropuertos), sino también las obras hidráulicas, las infraestructuras ambientales y las actuaciones en costas. En realidad es el plan de las competencias comprendidas dentro del Ministerio de Obras Públicas, Transportes y Medio Ambiente (MOPTMA) en aquellas fechas, con excepción de las de vivienda. Debe ser destacado el carácter pionero de este plan: por el esfuerzo por darle coherencia a sus propuestas más allá de la perspectiva específicamente sectorial de cada modo de transporte; por la adopción de criterios de ordenación y equilibrio territorial; por el análisis que se realiza de los efectos económicos y sobre la competitividad de la economía; por la inclusión de planes intermodales en áreas metropolitanas y las actuaciones de urbanismo y transporte, ambas concertadas con otras Administraciones; y por la incorporación de un capítulo específico sobre investigación y desarrollo en materia de infraestructuras. Este planteamiento posee un incuestionable valor, pero la inercia de funcionamiento sectorial del Ministerio primará sobre el mismo, y podríamos adelantar la conclusión de que prevalece hasta hoy.

Por lo que a las infraestructuras ferroviarias hace referencia, el PDI1993 contempla siete programas: Alta Velocidad, Actuaciones estructurantes, Actuaciones complementarias, Cercanías, Redes arteriales ferroviarias, Seguridad y pasos a nivel, Conservación y mantenimiento; a lo que habría que añadir otras inversiones, tales como las correspondientes a FEVE, o las actuaciones en puertos y de transporte combinado. En conjunto, el PDI1993 prevé una inversión en ferrocarril de 3,22 billones de pesetas en el periodo de referencia (recuérdese que el PTF1987 había fijado una inversión de 2,1 billones de pesetas siete años antes y para un periodo similar: 1987-2000). Con todo, el programa estrella del PDI1993 continúan siendo las carreteras con una inversión prevista de 5,47 billones de pesetas. De esta forma, mientras que las carreteras concentran el 50,1\% de las inversiones en los programas de transporte interurbano, el ferrocarril dispone del 30\% (PDI1993: 414).

Dentro de los diferentes programas recogidos en el PDI en infraestructuras ferroviarias, la atención se centra en las actuaciones de Alta Velocidad, pues debe tenerse presente que para esas fechas ya había entrado en servicio la línea de AV Madrid-Sevilla para deslumbre de muchos. Como bien expone A. Aparicio, la entrada en servicio de esta línea fue considerada más que como una actuación de modernización del ferrocarril, como un nuevo modo de transporte, de tal forma que "su principal efecto consiste en hacer desaparecer del imaginario colectivo el resto de la red de ferrocarril existente" (Aparicio, 2010: 11-12).

En términos generales, en el PDI1993 se mantuvo acotada la extensión de la alta velocidad al eje vertebrador central acordado en el Consejo de Ministros de 9 de diciembre de 1988, prolongado ahora hasta la frontera francesa, pero cuya ejecución queda fuera ya del marco presupuestario temporal del PDI1993. Posteriormente, "a largo plazo", se completaría con: a) un nuevo enlace con la red europea por el País Vasco y la conexión de las tres capitales vascas, denominada $Y$ vasca, con la dorsal central a través del corredor navarro; b) la extensión de la Alta Velocidad desde Madrid a Valencia; y c) la conexión con Portugal, cuyo 
trazado aún no se precisa (figura $\mathrm{n}^{\circ}$ 2): su similitud con el PTF1987 es evidente por lo que a los ejes principales o estructurantes se refiere. Asimismo, se afirma que el sistema ferroviario español estará formado por dos redes ferroviarias: la red de alta velocidad en ancho UIC, y la red convencional en ancho RENFE. La primera se diseña para tráfico exclusivo de viajeros, salvo algunas excepciones, y competitivo con el avión para atender a la demanda por motivos de negocio o trabajo. Es más, la Administración General del Estado, según recoge este Plan, considera que el desarrollo de la Alta Velocidad no debe ser financiado solo por los Presupuestos Generales del Estado, sino que deben participar también otras Administraciones territoriales y el capital privado (PDI1993: 148-149).

Figura $\mathrm{n}^{0} 2$

ALTA VELOCIDAD YACTUACIONES ESTRUCTURANTES

EN EL PLAN DIRECTOR DE INFRASTRUCTURAS (1993-2007)

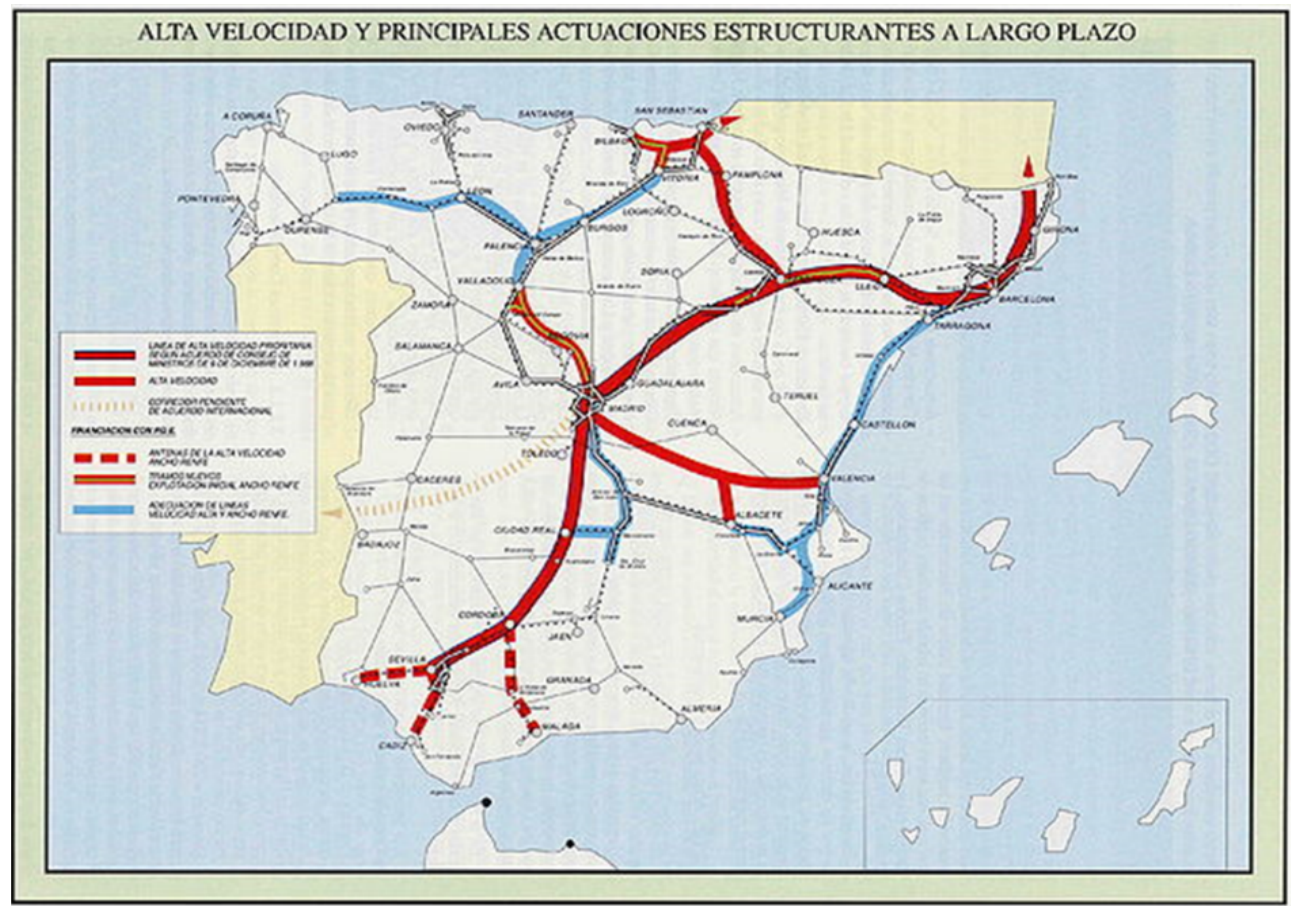

Fuente: Plan Director de Infraestructuras, 1994.

Al pasar de las musas al teatro se comprueba, primero, que de los 1.718 .000 millones de pesetas (MPtas) de inversión prevista en Alta Velocidad en el PDI1993, solo el 35\% será con cargo a los Presupuestos Generales del Estado (PGE), que se reduce al 28\% en los ajustes que realiza el PFI1995; el resto queda como inversión extra-PGE. Estas inversiones se van a concentrar, según el PFI1995, en la línea Madrid- Barcelona- Frontera Francesa (377.000 MPtas) y en la $Y$ vasca (160.000 MPtas); son de carácter testimonial en la línea Madrid-Valencia/Alicante y además retrasadas a 2009-2010 (20.000 MPtas) e inexistentes 
en el Corredor Navarro, del que se afirma expresamente que "desborda el horizonte temporal del PDI” (PIF1995, T II: 9 y 109). En el PFI1995 no hay ninguna previsión de aportaciones extrapresupuestarias, lo que no deja de ser una imprecisión demasiado llamativa en un documento de planificación a este nivel.

Al mismo tiempo, el PDI1993 identifica una serie de actuaciones que se denominan Actuaciones Estructurantes, mediante las cuales y a través de la modernización de las líneas, duplicación de vías, electrificación y construcción de nuevas variantes, en particular la Variante Norte (sierra de Guadarrama) y a más largo plazo la Variante de Pajares (en la Cordillera Cantábrica) se tiene como principal objetivo la elevación de la velocidad (a 200-220 km/h en unos casos, a $160 \mathrm{~km} / \mathrm{h}$ en otros) y la reducción de los tiempos de viaje. En tal sentido destacan las previsiones en el denominado ya en este documento Corredor Mediterráneo, que se considera prioritario por su carácter estructurante y vertebrador; en las relaciones hacia el norte de Madrid, a través de la variante de igual nombre; y en las líneas de conexión de Valladolid con el País Vasco hacia el noreste y con León y Galicia hacia el noroeste. Por último, en el sur se diseñan las denominadas antenas hacia Málaga, Cádiz y Huelva, con el objetivo de extender los beneficios de la alta velocidad hacia esas tres capitales andaluzas: mediante actuaciones de renovación o modernización y la conexión con la red de alta velocidad en Sevilla o Córdoba, se mejorarían sensiblemente su relación con el centro peninsular. En todas las actuaciones estructurantes se mantiene el ancho de vía RENFE, por lo que se deberán desarrollar las técnicas de compatibilidad entre una ancho y otro, ya mencionadas.

El PFI1995 presupuesta 969.694 MPtas en el programa de Actuaciones Estructurantes, mientras que la inversión en Alta Velocidad a cargo de los PGE se cifra en 557.000 MPtas; ello puede dar una idea de que, a pesar de la aparente prioridad de la Alta Velocidad, el objetivo del Ministerio sigue siendo la modernización de la red convencional para conseguir velocidades más competitiva con la carretera en este primer nivel de la red convencional en ancho RENFE, cifra a la que habría que sumar la inversiones prevista en las denominadas Actuaciones complementarias en renovaciones de vías y rectificaciones de trazado. Mediante estas se pretende extender los beneficios de la Alta Velocidad a otros territorios peninsulares y, posiblemente, dar respuesta política a diferentes demandas territoriales (Galicia, Cantabria, $2^{a}$ conexión con Portugal desde Salamanca, Extremadura, Andalucía Oriental y puerto de Algeciras, como los más significativos).

En la programación de las inversiones en las actuaciones estructurantes (figura $\mathrm{n}^{\mathrm{o}} 3$ ), se aprecia la prioridad dada al Corredor Mediterráneo desde Barcelona a Murcia, así como la conexión con Albacete, tanto por el volumen de inversión (220,2 MPtas y 22,7\% del total del las inversiones en este programa), como por su programación en los primeros años de ejecución del Plan; la previsión del plan es que en este corredor se mantenga el ancho de vía RENFE y se compatibilice la circulación de viajeros y mercancías. En segundo término, se sitúan las obras de la Variante Norte hacia Valladolid con un nuevo túnel en la Sierra de Guadarrama (200.000 MPtas, 20,6\% del programa), cuya ejecución se iniciaría en 1998 y con la previsión de mantenerla en el mismo ancho, al menos en el horizonte del PDI1993. En tercer lugar la inversión de mayor alcance contemplada es el acceso a Galicia (160.000 MPtas, 16,5\% del programa), que se iniciaria a partir de 1999. En principio, el acceso a Galicia está planteado desde León y Ponferrada a Ourense; sin 
embargo, ya en el PFI1995 se aportan datos básicos del coste de la actuación y tiempos de recorrido desde León-Ponferrada y desde Medina-Zamora, ambos con destino en Ourense, y se apunta que el segundo trazado, el acceso sur, sería más favorable en términos de tiempo de recorrido y coste de la actuación; pero deja abierta la decisión final que se vaya a adoptar (PIF1995, T ${ }^{\circ}$ II: 114-118 y figura $n^{\circ} 3$ ). Actualmente la línea en ejecución es la del acceso sur, pero los planes de infraestructuras posteriores no han renunciado al acceso desde León-Ponferrada.

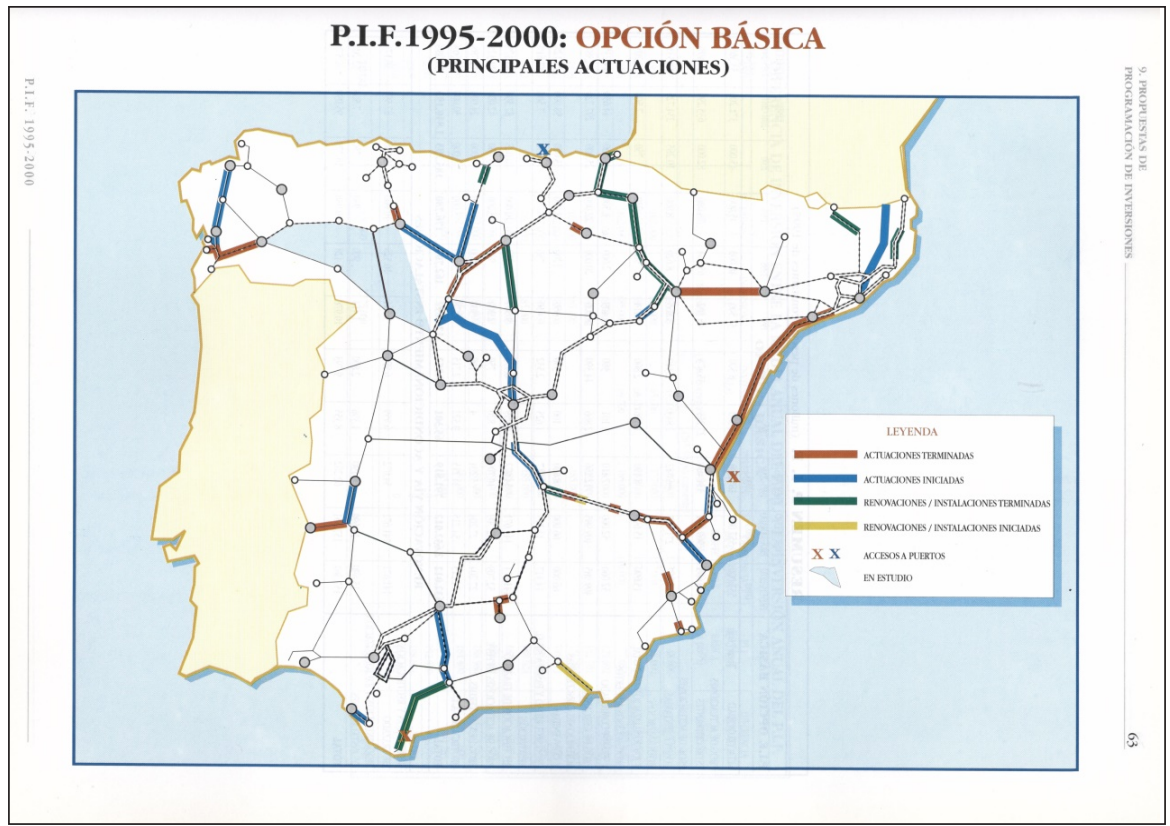

Fuente: Plan de Infraestructuras Ferroviarias 1995-2000.

Si se hace abstracción, lo que no resulta fácil, de la incorporación de la dorsal vertebradora central en ancho UIC, el PDI1993 y el PIF1995 que lo desarrolla mantienen grandes similitudes con los objetivos y propuestas del PTF1987. En este último el objetivo perseguido, en la mejora de la red y ganancia de competitividad con la carretera, se mide en términos de la velocidad a alcanzar en distintos trayectos; en el segundo, se mantienen como prioritarios prácticamente los mismos ejes que en el primero y el dato más preciso continúa siendo el de la velocidad a alcanzar, aunque se echa en falta en el PIF1995 un mayor detalle de las actuaciones, según cada caso. Sí se especifica el ancho de la vía en cada trayecto; son excepcionales las referencias a trayectos que pueden cambiar del ancho RENFE al ancho UIC y al uso de traviesas polivalentes; y no hay ninguna referencia a una extensión generalizada del ancho UIC en la red española, sino a la coexistencia de ambos anchos. 


\section{EL PLAN DE INFRAESTRUCTURAS DE TRANSPORTE 2000-2007 (PIT2000)}

No es posible situar al denominado Plan de Infraestructuras de Transporte 2000-2007 al mismo nivel que su precedente (PDI1993) o los que se elaboraron con posterioridad. No hay constancia de su tramitación, ni de su aprobación, ya fuese por el Congreso de los Diputados, por el Consejo de Ministros o por el Ministerio correspondiente; no se dispone de un documento elaborado que recoja objetivos, programas y propuestas. Pero lo cierto es que con la llegada de F. Álvarez Cascos al Ministerio de Fomento en el año 2000 se empieza a hablar de un Plan de Infraestructuras, que termina denominándose Plan de Infraestructuras de Transporte 2000-2007 (PIT2000). Al inicio del periodo, el entonces Director de Programación Económica del Ministerio de Fomento publica un artículo en la Revista de Obras Públicas en el que habla del Plan General de Infraestructuras (López Corral, 2000), con una inversión de 17,1 billones de pesetas en el periodo 2000-2010.

De acuerdo con la información recogida en ese artículo, las inversiones en ferrocarriles $(39,8 \%)$ y carreteras $(38,6 \%)$ se encuentran equilibradas en las previsiones del Ministerio. Cuatro años después, el mismo Director General realiza un balance de la ejecución del PIT2000 y afirma que las previsiones de inversión para ese periodo han sido superadas y el ferrocarril ha pasado a ocupar la primera posición en el montante de las inversiones del Grupo Fomento, de forma que en 2003 han supuesto el 46,2\%, frente al 27,0\% en carreteras (López Corral, 2004: 17). Según sus palabras: "En el capítulo ferroviario, la alta velocidad ha sido, y es, la gran apuesta del PIT2000-2007 como medio de transporte de futuro, siguiendo las orientaciones de la Unión Europea" (López Corral, 2004: 9). El objetivo es construir una red de alta velocidad, sin mayores especificaciones técnicas, de 7.131 kilómetros de extensión y que conecte todas las capitales de provincia.

Si una imagen vale más que mil palabras, ninguna imagen ha hecho más por la extensión homogeneizadora de la Alta Velocidad en España que la que se recoge en la figura $\mathrm{n}^{\circ}$ 4 (fechada el 31 de diciembre de 2001). Desde este momento queda consolidada en el imaginario político español el derecho de todas las capitales de provincia a acceder a la red de alta velocidad $^{1}$. En la construcción de esta imagen, el objetivo hubo de ser el de dibujar el trayecto más corto para que todas las capitales de provincia quedasen incorporadas a la red buscando siempre la conexión con el centro. De ese modo, se obtiene un grafo en árbol, con todas las capitales conectadas o colgadas de Madrid, en primer o segundo nivel, y en consecuencia bastante de ellas como final de trayecto o fondo de saco (Granada, Almería, Jaén, Ávila, Salamanca, Soria, Teruel, Huesca, Logroño, Pamplona, o Lugo). Solo el corredor mediterráneo, de Figueras a Almería, escaparía a esa lógica; en cambio se rompe la conexión navarra con la Y vasca, una de las actuaciones estructurantes y prioritarias de los planes anteriores.

1 Desde entonces, los Presidentes de Gobierno, desde Aznar a Rajoy, pasando por Rodríguez Zapatero, han fijado como el gran objetivo de la política de infraestructura ferroviaria la conexión de todas las capitales de provincia a la red de alta velocidad, pero elevando cada vez más el listón. El último, Rajoy, prometía en Badajoz en la campaña autonómica de 2007 que todas las capitales de provincia estarían unidas por AVE a $350 \mathrm{~km} / \mathrm{h}$. http://www. elmundo.es/elmundo/2007/05/21/espana/1179752036.html 


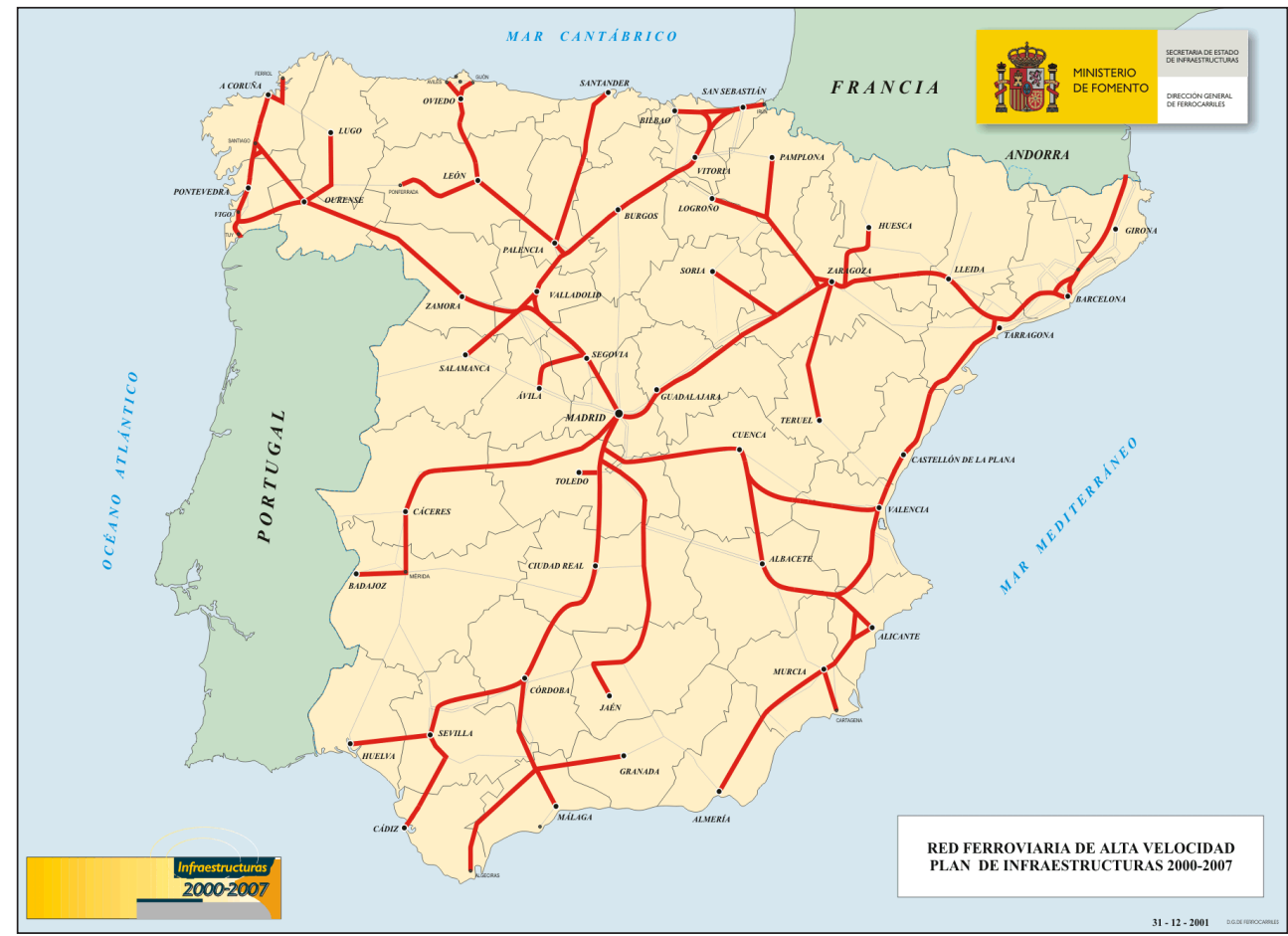

Fuente http://www.miliarium.com/Monografias/AVE/Plan_Infr_Ferrov.gif

Con posterioridad, esta imagen uniforme y plana se completa incorporando información sobre el estado de cada tramo, con diferenciación de: en Servicio, Obras, Proyecto, Estudio Informativo pendiente de Declaración de Impacto Ambiental (DIA), o simplemente en Estudio Informativo, de incierto significado y desarrollo (figura $\mathrm{n}^{\circ} 5$ ).

De esta imagen, fechada el 23 de 0ctubre de 2003, cabe destacar el trayecto efectivamente ya en servicio en Alta Velocidad en ancho UIC: Sevilla-Madrid-Lleida. También se incluye en esa misma categoría (o leyenda de la imagen) un tramo del Corredor Mediterráneo, que dispone de doble vía electrificada en ancho ibérico; en realidad en este tramo se han podido llevar a cabo las mejoras previstas en los planes anteriores, pero en ningún caso se ha construido una línea de alta velocidad. Una confusión interesada, que se ha mantenido con posterioridad, y que hará emerger más adelante la reivindicación del Corredor Mediterráneo como corredor de alta velocidad; para estas fechas (2003) se habrían llevado a cabo las previsiones de renovación y mejoras contempladas en el PDI1993 y en el PTF1987, pero no la construcción de una nueva línea con las prescripciones de la alta velocidad. En obras, en ancho UIC, se encuentran los trayectos Lleida-Tarragona-Barcelona, Madrid-Valladolid (la variante Norte de planes anteriores, donde se está construyendo un túnel de $28 \mathrm{~km}$ ), Córdoba-Málaga (en ningún caso prioritario en el PTF1987 y contemplada como antena 
en ancho ibérico en el PDI1993). En cambio se retrasa la conexión con el País Vasco, prevista ahora desde Valladolid y Burgos, y la de Lisboa. Así, algunas de las principales actuaciones establecidas en planes anteriores han quedado relegadas y, en cambio, se están desarrollando otras que no había sido considerada como tal anteriormente, lo que pone de manifiesto que, tras el plan, está la decisión política, que puede conllevar razones de carácter financiero, por la posibilidad de disponer de más Fondos de Cohesión europeos en unos territorios que en otros.

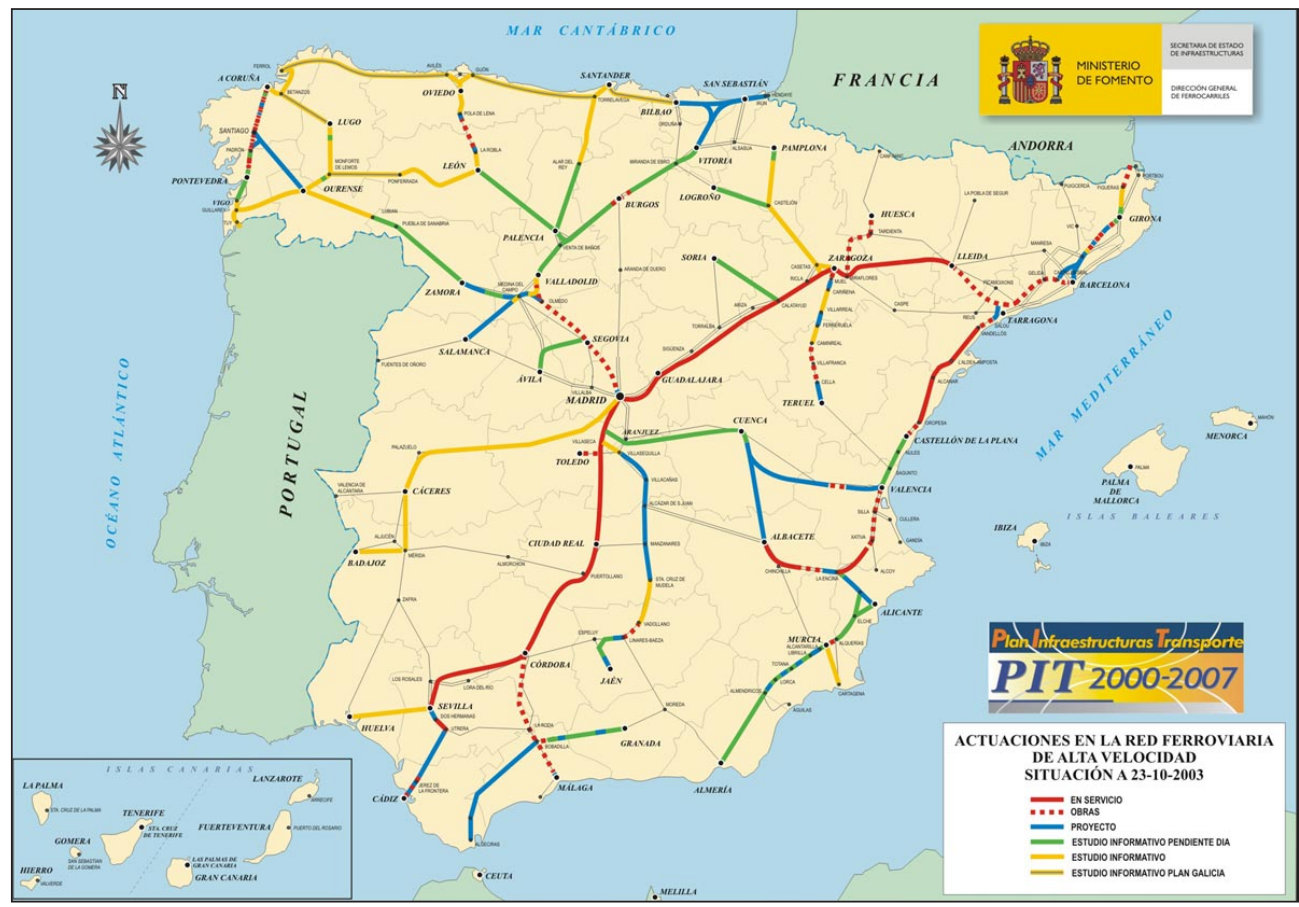

Fuente: http://3.bp.blogspot.com/-nm4E05OyesY/UfUJWv1VnoI/AAAAAAAAJYE/GCyRqZpRAWo/s1600/ renfe-pit-00-07.jpg

Debe llamarse la atención sobre la última leyenda recogida en la figura n $\mathrm{n}^{\circ}$ : "Estudio Informativo Plan Galicia". Es necesario recordar en este punto el grave desastre ecológico que para las costas gallegas y economías vinculadas supuso el hundimiento del petrolero Prestige y el subsiguiente vertido de su carga de fuelóleo de alta viscosidad, el 13 de noviembre de 2002. En un Consejo de Ministros celebrado en A Coruña el 24 de enero de 2003 se aprobó el denominado Plan Galicia, que recogía un volumen de inversiones de $12.459 \mathrm{MEu}$ ros con el objetivo de ayudar a la recuperación de la economía gallega tan dañada, y en el que se incluía un alto volumen de inversiones en infraestructuras, algunas ya programadas y otras nuevas. Por lo que hace referencia al objeto de este trabajo, se plantea: 
- "Inicio de la planificación del corredor ferroviario de AVE del Cantábrico (El FerrolAsturias-Cantabria-Bilbao), corredor que tendrá una inversión en el tramo gallego de 1.476 millones de euros.

- Inicio de los estudios de trazado de la conexión de Alta Velocidad Ponferrada-Monforte, con una inversión para este trazado en el tramo gallego de 690 millones de euros.

- Inicio de los estudios de trazado de la conexión de Alta Velocidad Lugo-A Coruña, trazado que contará con una inversión de 780 millones de euros.

- Solución de doble túnel y alta velocidad en el tramo ferroviario Lubián-Orense"2

Algunas reflexiones finales al hilo de ello:

a) No es el único caso que el Gobierno reacciona prometiendo inversiones en infraestructuras para responder o paliar una situación crítica producto del azar, las condiciones naturales o la mala gestión de los mismos. Pero estas infraestructuras ni guardan relación con el origen del problema, ni van a contribuir a mitigar sus consecuencias, salvo el efecto que pueda tener en el empleo, en cualquier caso temporal y a medio plazo.

b) Se colige que un Plan de infraestructuras puede ser modificado por una decisión política en los términos que aquí se ha hecho sin más que como consecuencia de un trágico avatar y su deficiente gestión.

c) La oposición criticó el Plan Galicia, pero, con posterioridad, con esa oposición en el poder y con un nuevo Plan de Infraestructuras, no se corrige tal decisión. Los corredores recogidos en este acuerdo del Consejo de Ministros como Plan Galicia se han mantenido en los sucesivos planes, aunque no se ha producido avance en su desarrollo, salvo en el punto referido al tramo Lubián-Ourense.

\section{EL PLAN ESTRATÉGICO DE INFRAESTRUCTURAS Y TRANSPORTES 2005-2020 (PEIT2005)}

El PEIT2005 responde a una promesa electoral del Partido Socialista, recogida por el Presidente Rodríguez Zapatero en su discurso de investidura como una de las prioridades de su gobierno dentro del bloque dedicado a la modernización e impulso a la economía ${ }^{3}$. Ha sido el primer plan sometido a un procedimiento reglado en su elaboración, con consultas a las Comunidades Autónomas, Información Pública y sometimiento a evaluación ambiental y se incardina dentro de las Directivas relativas a la ordenación de los transportes en la Unión Europea. Fue aprobado por el Consejo de Ministros en su sesión del 15 de julio de 2005

Como tal Plan Estratégico pretende establecer las grandes líneas de actuación en el sistema de transporte, tanto en el conjunto del sistema -intermodalidad ("el sistema de trans-

2 Referencia del Consejo de Ministros del 24 de enero de 2003: http://www.lamoncloa.gob.es/consejodeministros/referencias/Paginas/2003/c2401030.aspx\#comisióninterministerial

3 "No es cuestión de enumerar ahora los compromisos que hemos asumido en el programa electoral en cuanto a las infraestructuras del transporte ... todas ellas se abordarán con estrictos criterios ambientales... antes de finales del año en curso el Gobierno aprobará el Plan Nacional de Transportes e Infraestructuras y lo enviará al Parlamento para su debate" http://www.congreso.es/public_oficiales/L8/CONG/DS/PL/PL_002.PDF 
porte se concibe como una red de redes" PEIT2005: 55), seguridad, calidad y eficiencia, equilibrio territorial, financiación del sistema en su conjunto, o la cooperación interadministrativa-- como en las directrices específicas para cada una de las políticas sectoriales. El PEIT2005 pretende que sus planteamientos estratégicos sean desarrollados por una batería de instrumentos normativos y de planificación (PEIT2005: 145-146) ${ }^{4}$, pero que no han sido llevados a efecto, si bien se elaboraron algunos borradores de planes o normas, que no terminaron siendo aprobados ${ }^{5}$.

En el caso del ferrocarril, el PEIT2005 recoge hasta dieciséis directrices generales, figurando en primer lugar la consolidación del nuevo modelo ferroviario basado en la separación de la gestión de la infraestructura y los servicios, en cumplimiento de Directivas europeas y de la Ley 39/2003, del Sector Ferroviario, y que da lugar a la creación de dos empresas públicas: la responsable de las infraestructuras (ADIF) y la de los servicios ferroviarios (que mantiene la denominación de la antigua empresa estatal RENFE, por razones comerciales).

Entre tales directrices destacan las relativas a la interoperabilidad de la red española con el resto de la red europea, siguiendo las Directivas 96/48/CE y 2001/16/CE. La interoperabilidad depende de varios factores, tales como la electrificación, condiciones de explotación o los sistemas de señalización; pero en el caso español la más destacable y de mayor complejidad para su implantación es el cambio de ancho de vía, que este plan estratégico asume como una de sus prioridades. En el PEIT2005 se toma la decisión de proceder, de forma paulatina y progresiva, a la sustitución del ancho convencional, ancho ibérico o ancho RENFE, por el ancho internacional, ancho standard o UIC, estableciéndose como prioritario el cuadrante nordeste, por su proximidad al acceso a Francia por Cataluña. Para su consecución se plantea también el uso generalizado de las técnicas de compatibilización entre ambos anchos, tanto en el material rodante, como en la infraestructura: "implantación sistemática de traviesa polivalente en vía ibérica para preparar el cambio de ancho" (PEIT2005: 93).

En paralelo se proyecta una extensa red denominada de altas prestaciones, diseñada básicamente para tráfico mixto de viajeros y mercancías, salvo algunos itinerarios ya construidos o en ejecución (figura $n^{\circ} 6$ ), que quedan para tráfico exclusivo de viajeros. Las tres propuestas (extensión de la red, altas prestaciones y tráfico mixto) han de ser contempladas conjuntamente.

4 El PEIT2005 contempla la elaboración de 8 planes sectoriales propios del Ministerio de Fomento, Planes de Movilidad Sostenible concertados con las Administraciones territoriales, así como la elaboración de 3 nuevas leyes (Ley Marco de Financiación del Transporte y de Ordenación de los Sistemas Tarifarios, Ley de Financiación del Transporte Urbano y Metropolitano y Ley de Aeropuertos y de Navegación Aérea), además de la revisión de otras existentes o su desarrollo normativo. En 2012, el Ministerio anunciaba de nuevo la presentación de una Ley de Financiación del Transporte que tampoco ha culminado su proceso.

5 El Ministerio presentó algunos documentos, como los denominados Plan de Seguridad en pasos a nivel 2005-2012 o Plan Estratégico para el impulso del transporte de mercancías en España, en 2010, con información precisa de diagnóstico o sobre actuaciones previstas, que no han seguido una tramitación reglada, pero sí son documentos de referencia para la acción del Ministerio u organismos dependientes. 


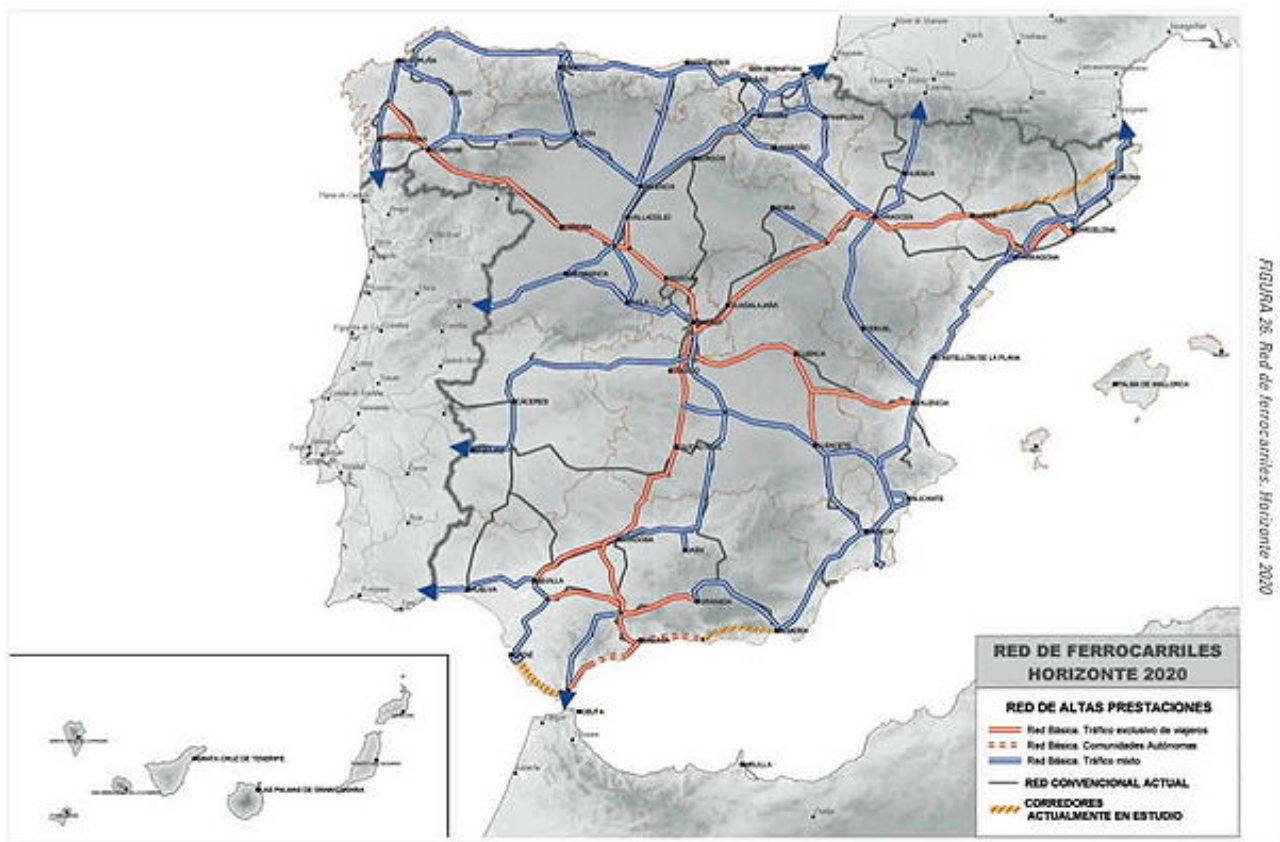

Fuente: Plan de Infraestructuras y Transportes 2005-2020.

La red de altas prestaciones que diseña el PEIT en el horizonte de su ejecución (2020) cierra un mayor número de itinerarios en relación con la propuesta precedente: entre Navarra y el País Vasco, entre Aragón y Valencia, en la conexión entre Madrid, Avila, Salamanca y la frontera portuguesa y el eje transversal interior en Andalucía; consolida el acceso a Galicia también desde León-Ponferrada, así como el corredor cantábrico. Se recogen nuevos "corredores en estudio", en Andalucía y Cataluña, que responden a propuestas de ambas Comunidades Autónomas. El resultado es una red más mallada de 10.000 kilómetros y una inversión en infraestructuras ferroviarias de 103.410 M€, el 43,84\% del total del PEIT, correspondiendo $83.450 \mathrm{M} €(76,7 \%)$ a inversiones en altas prestaciones ${ }^{6}$ (PEIT2005: 167).

En principio, el término altas prestaciones puede considerarse equiparable a la alta velocidad por sus características técnicas y condiciones de seguridad y servicio. Pero el PEIT2005 admite que "de manera transitoria algunas líneas de la red ferroviaria de altas prestaciones puede mantener el ancho ibérico" (PEIT2005: 172). Por otra parte, establece tres situaciones distintas para los corredores de altas prestaciones (PEIT2005: 92-93). Junto

6 En términos de financiación, y en comparación a lo establecido en el PDI1993, solo el 18,6\% procederá de fuentes de financiación extrapresupuestaria, y las restantes se harán a cargo de lo Presupuestos Generales del Estado, sin mención alguna a la participación de otros Administraciones territoriales o al sector privado. 
a las líneas de nuevo trazado y tráfico exclusivo de viajeros, se contemplan otras situaciones en las que la actuación supondrá una "variación sustancial del trazado" en unos casos, o de "renovación integral de estos tramos" en otros, al tratarse de líneas de menor tráfico, lo que a su vez permite la compatibilización de los tráficos de viajeros y mercancías. Se establece una relación entre volumen de tráfico, tipo de actuaciones y tráfico exclusivo o mixto, aunque con un alto grado de indeterminación por lo que al volumen de tráfico respecta ("que superen un determinado umbral de tráfico", "líneas de tráfico medio", o "con tráfico sensiblemente menor") y sin que esas tres aparentes categorías queden reflejadas en las imágenes básicas del PEIT.

Al mismo tiempo se deja abierta la posibilidad, en función de los tráficos alcanzados, de modificar el diseño previsto en los corredores de tráfico mixto, tanto en el sentido de cerrar líneas convencionales (al pasar su tráfico a las líneas nuevas), como de incrementar el número de líneas en un mismo corredor: "En estos casos, y en especial en los ejes de mayor tráfico, como son entre otros el Corredor Mediterráneo o el Valladolid-Burgos-Vitoria, el diseño de tráfico mix to previsto por el PEIT debe entenderse aplicado al ámbito del corredor, no de la línea concreta, de forma que si las condiciones de tráfico, funcionalidad y servicio así lo determinaran, en parte o en su totalidad podrán establecerse en ellos líneas paralelas de carácter especializado" (PEIT2005: 93).

En síntesis: Un diseño ambicioso en su extensión que responde al afán político de superar propuestas precedentes y atender a las diferentes reclamaciones territoriales, un intento de base técnica de ajustar las actuaciones a las necesidades de la demanda del tráfico ferroviario, y un alto margen de ambigüedad o imprecisión para salvar el puente entre ambos extremos.

\section{EL PLAN DE INFRAESTRUCTURAS, TRANSPORTE Y VIVIENDA 2012-2024 (PITVI2012)}

Formalmente el PITVI2012 es un plan que sigue una rigurosa tramitación: desde su presentación al Consejo de Ministros, e información a las Cortes (Congreso de los Diputados, 2012), apertura de información pública en septiembre de 2012, elaboración del Informe de Sostenibilidad Ambiental y nueva información pública en enero de 2014 y finalmente el Secretario de Estado formula el documento final del Plan por Resolución del 5 de mayo de $2015^{7}$. El PITVI2012 incorpora todas las competencias que ostenta en Ministerio de Fomento en esa legislatura, tanto las de infraestructuras del transporte como las de vivienda, y es una de las razones aducidas para justificar la elaboración de este plan; pero ni la naturaleza del objeto a planificar, ni las competencias de la Administración General del Estado en unas u otra explican este tratamiento conjunto. En cualquier caso, se trata de dos documentos independientes, solo unidos por el título del plan, que han seguido una misma tramitación. Así, el PITVI2012 viene a consolidar una práctica política consistente en reiniciar, aparentemente

7 RESOLUCIÓN de la Secretaria de Estado de Infraestructura, Transporte y Vivienda por la que se formula el documento final del Plan de Infraestructura, Transporte y Vivienda, 15 de mayo de 2015. http://www.fomento. gob.es/NR/rdonlyres/9C7046DD-BEF6-4DD4-B6E4-4E3ADAF6DB60/130924/ResolucionSEPITVI.pdf. Realizada la tramitación indicada, el PITVI es aprobado por el Secretario de Estado y no por el Consejo de Ministros como se hizo en el caso del PDI1993 y del PEIT2005; el Plan fue presentado al Consejo de Ministros en agosto de 2012, y posteriormente se llevó a la Comisión de Fomento del Congreso para información. 
en posiciones diametralmente distintas a las precedentes, un nuevo plan de infraestructuras a nivel estatal, incluso ignorando la existencia del plan en vigor. En el debate sobre el peso de las posiciones técnicas y políticas en torno a la teoría de la planificación (Benabent, 2014), en la de las infraestructuras del transporte en España toma protagonismo la decisión política, con independencia del contenido técnico de lo que se planifica.

Los planteamientos del PITVI2012 se han movido entre distintos polos. Por una parte, se sitúa el marco macroeconómico; es decir, la profunda crisis económica, que a la fecha de elaboración del PITVI2012 se traduce en descenso de los tráficos en todos los modos de transporte y una drástica reducción de las inversiones públicas en nuevas infraestructuras que lleva a la ralentización o paralización de obras en proceso de ejecución ${ }^{8}$. El PITVI2012 manifiesta una posición cauta en relación con la capacidad inversora pública, situándola en el entorno del $0,90 \%$ del PIB, habiéndolo fijado el PEIT en el 1,5\%; pero al mismo tiempo mantiene como uno de los principales objetivos de la planificación o "principios programáticos" la utilización de la planificación de las infraestructuras para la superación de la crisis económica9 ${ }^{9}$. Un segundo polo viene constituido por la aprobación de nuevas Directivas de la Unión Europea, que marcan la orientación de las políticas de transporte, ya muy presentes en la fase precedente, pero que van adquiriendo mayor consolidación, desde Directivas sobre redes transeuropeas, seguridad, gestión integrada o liberalización de los servicios en general, a la Directiva 2012/34/UE sobre el Espacio Ferroviario Único Europea en particular para el ferrocarril ${ }^{10}$. Finalmente, como tercer polo destaca su atención al sector privado, al plantear una mayor participación del mismo en la gestión de las infraestructuras y los servicios del transportes en la tesis de la mayor eficiencia de este sector, así como las declaraciones explícitas que se realizan al apoyo a las empresas españolas en su internacionalización, cuestión a nuestro juicio alejada de la planificación (PITVI2012: 64-65 y 88-89).

Respecto al sistema ferroviario, en el diagnóstico se destaca la existencia de $2.344 \mathrm{~km}$ de Alta Velocidad y $810 \mathrm{~km}$ "adaptados a la Alta Velocidad"11 ; pero en la red convencional $(11.597 \mathrm{~km})$ se mantiene un $70 \%$ en vía única, un $46 \%$ de la misma no está electrificada

8 Los PGE2008 contemplaban un volumen de inversión del Grupo Fomento de 17.930 M€ y los PGE2012 de 11.114M€. Para 2008: ROJAS y CHAMORRO, (2008) http://www.ief.es/documentos/recursos/publicaciones/revistas/presu_gasto_publico/50_PresupuestoGrupoFomento.pdf; y para 2012: http://myslide.es/documents/ proyecto-de-presupuesto-2012-0-ministerio-de-fomento-proyecto-de-presupuesto-2012.html. Dado el carácter plurianual de la programación de las inversiones en grandes obras de infraestructuras, difícilmente los Presupuestos de 2012 vienen a cubrir obras contratadas dos o tres años antes.

9 "Utilizar la planificación de las infraestructuras y la política de transporte asociada como instrumentos de la política económica, coadyuvando a articular una estrategia macro de respuesta y superación de la crisis económica" (PITVI2012, p. 56) O "La planificación de las infraestructuras se concibe como una herramienta de la política económica orientada a contribuir al desarrollo económico y social de España y a la superación de la coyuntura adversa actual" (PITVI2012, p. 64)

10 Mención aparte merecería las sucesivas propuestas de la Unión Europea sobre Redes Transeuropeas (RTET) y sus proyectos “prioritarios”, en particular el Reglamento (UE) 1315/2013 con horizonte de ejecución en 2050, y su relación con los últimos planes.

11 Se supone que de acuerdo con la definición de Alta Velocidad que ya se incluía en la Decisión 1692/ EC del Parlamento Europeo y el Consejo, de 23 de julio de 1996, y posteriormente en el Real Decreto 1434/2010, de 5 de noviembre, sobre interoperabilidad del sistema ferroviario de la Red Ferroviaria de interés general. En ambos se consideran también líneas de Alta Velocidad las "especialmente acondicionadas" para la AV donde se pueden alcanzar velocidades "del orden" de $200 \mathrm{~km} / \mathrm{h}$ : http://eur-lex.europa.eu/LexUriServ/LexUriServ. do?uri=CELEX:31996D1692:ES:HTML y https://www.boe.es/boe/dias/2010/11/06/pdfs/BOE-A-2010-17037.pdf. 
y solo en 1/3 de la red se puede circular a más de $160 \mathrm{~km} / \mathrm{h}$ (PITVI2012: 29-30). Estas cifras confirman la brecha existente en el sistema ferroviario español entre la red de alta velocidad y la red convencional. El PITVI cuestiona el tráfico mixto propuesto en el PEIT y apunta a la utilización para las mercancías de las líneas convencionales liberadas del tráfico de viajeros por la construcción de las de alta velocidad. Insiste en las asignaturas pendientes del ferrocarril en España: el tráfico de mercancías que continúa perdiendo cuota de mercado, la interoperabilidad del sistema ferroviario que requiere el cambio de ancho en toda la red, o la intermodalidad con otros modos de transporte. Pero la mayor parte de sus propuestas o son imprecisas o son remitidas a un desarrollo posterior.

En el Programa de Actuación Inversora (PITVI2012: 151-158) se enfatizan los principios de eficiencia y sostenibilidad, la necesidad de replanificar las inversiones y se plantea la realización de análisis de viabilidad de líneas con débil tráfico y eventualmente su cierre (PITVI2012: 125-126). En relación a la alta velocidad es muy ambiguo sobre su expansión ${ }^{12}$ y fija dos prioridades: obras en ejecución y los ejes con elevada potencialidad de captación de tráfico, pero sin mayor precisión o concreción. Todos estos buenos principios de planificación quedan en entredicho en el capítulo 6 y en particular en el apartado sobre Nuevas Inversiones en Alta Velocidad (PITVI2012: 200-202) donde se incluyen casi todas las previsiones del plan anterior, e incluso se incorporan algunas nuevas. No se precisa ni la fecha horizonte para la culminación de dicha $\operatorname{red}^{13}$, ni la extensión en kilómetros de la red completa.

En comparación con el PEIT, se prescinde de la conexión directa entre Madrid, Ávila y Salamanca, eje sensiblemente paralelo al Madrid-Segovia-Zamora; se elimina el corredor en estudio en el interior de Cataluña y se rebaja a esta condición la conexión entre Huesca y la frontera francesa. Pero a su vez incorpora nuevos ejes: en Andalucía se consolida un doble trazado del Corredor Mediterráneo, por la costa y por el interior y conexiones entre ambos ejes, de muy costosa ejecución, fuerte impacto ambiental y muy dudosa rentabilidad económica; también se propone un doble trazado en el Corredor Mediterráneo entre Castellón y Tarragona, que puede responder a la reclamación de que este corredor esté dotado de cuatro vías, dos para tráfico de mercancías y otras tantas para viajeros, pero sin que haya ninguna precisión al respecto en el plan; y como nuevo corredor en estudio se incorpora la conexión entre León, Zamora y Cáceres, sector norte de una ruta de la Plata ferroviaria, línea cerrada al tráfico en la década de los ochenta del siglo pasado.

Todo ello con menores disponibilidades de recursos económicos, dentro del marco de austeridad y equilibrio presupuestario ${ }^{14}$. Por otra parte, en el anexo de actuaciones, para una misma línea, se prevén tanto "actuaciones en reposición de la red convencional" como "nuevas inversiones en alta velocidad", y ello en un plan que, como ya ha sido indicado, considera que no es compatible el tráfico mixto en líneas de alta velocidad y que debe

12 "La sostenibilidad de la extensión de este modelo (en referencia a la Alta Velocidad) a relaciones con menor potencialidad de demanda se ve negativamente condicionada por las circunstancias de la economía" (PITVI2012, p. 52).

13 En el documento de septiembre de 2012, se vinculaba esta propuesta al Horizonte de la Red de Transporte Europea a largo plazo, en 2050. Pero tal referencia ha desaparecido del documento final.

14 Ambos planes (PEIT y PITVI) dedican el 44\% de sus inversiones al capítulo ferroviario, que en caso del PEIT se traducen en 108.760M€ en 16 años, y en el del PITVI en 61.302M€ en 13 años. 
utilizarse las líneas convencionales para el tráfico de mercancías, lo que no parece guardar gran coherencia. Finalmente ha prevalecido de nuevo la lógica política, aún en un escenario de acusada crisis económica.

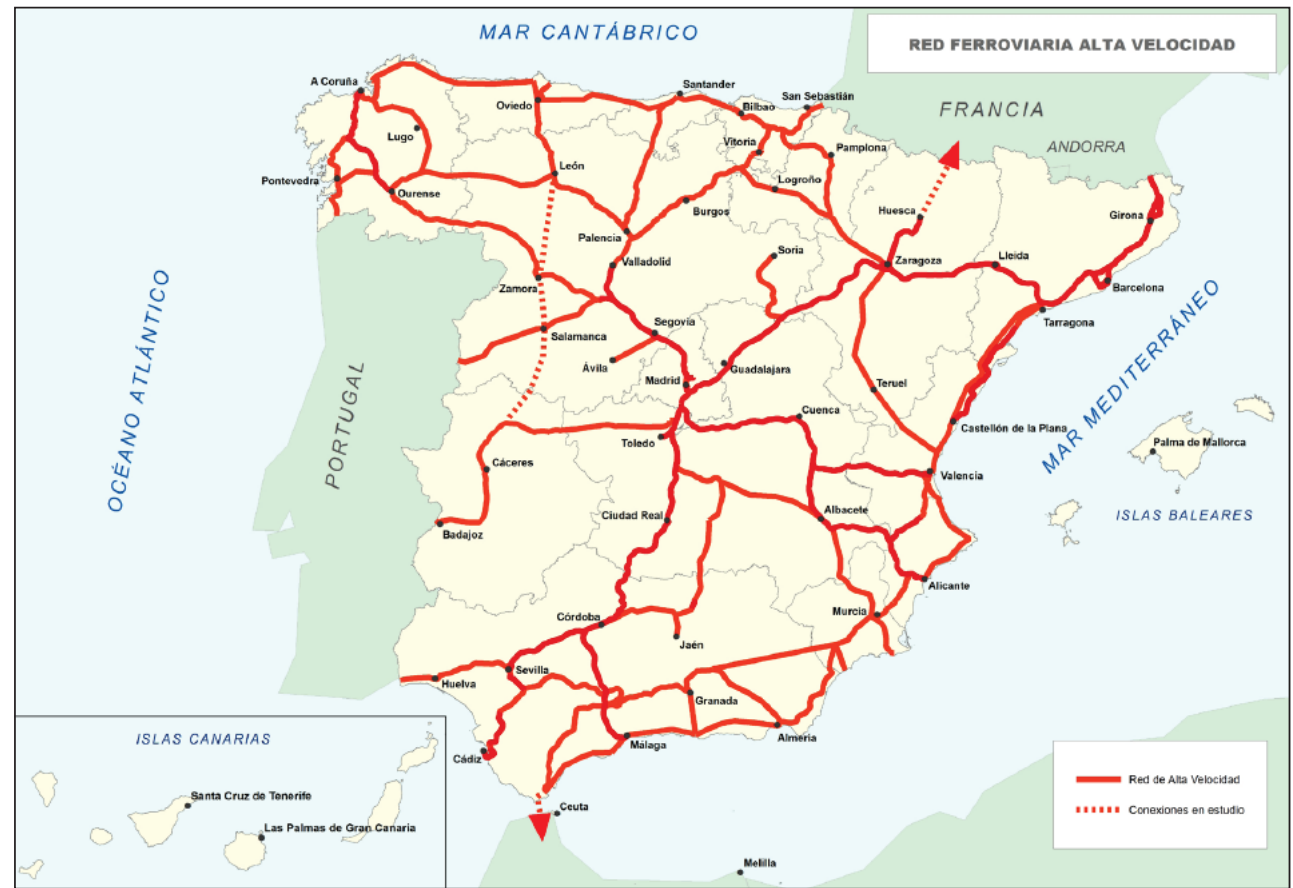

Fuente: Plan de Infraestructuras, Transporte y Vivienda, 2012-2024.

\section{RESULTADOS}

Treinta años después de la aprobación del Plan del Transporte Ferroviario de 1987 y veinticinco años desde la inauguración de la LAV Madrid-Sevilla en 1992, la gran transformación operada en el sistema ferroviario español ha sido la puesta en servicio de una red de alta velocidad, de la que recurrentemente se repite que es la más extensa de Europa. No hay acuerdo en los kilómetros en servicio. En unos casos la falta de actualización de las fuentes, en otros, la consideración como tal de líneas "adaptadas a la alta velocidad" o de líneas convencionales sensiblemente mejoradas, pero que mantienen el ancho ibérico, u otras circunstancias, llevan a que se manejen distintos números: el último Observatorio Ferroviario de España (OFE) disponible da la cifra de 2.471,1 km de los cuales 84,1 km en ancho ibérico y 151,9 km en vía única, a 31 de diciembre de 2014 (OFE2014: 20); el Anuario Estadístico del Ministerio de Fomento de 2014 proporciona la cifra de 2.829,96 km de red de alta velocidad, de los cuales 567,34 en ancho ibérico y 336,07 sin electrificar, de los cuales 286,29 en vía 
única, sin que se aporte explicación a esta singularidad (Ministerio de Fomento, 2014: 2); por su parte ADIF, en su página web, fija en 3.143 los kilómetros de alta velocidad en España ${ }^{15}$. En relación a su diseño territorial, la red de alta velocidad en servicio es de carácter marcadamente radial, centrada en Madrid; la figura $\mathrm{n}^{\circ} 8$ se comenta por sí sola.

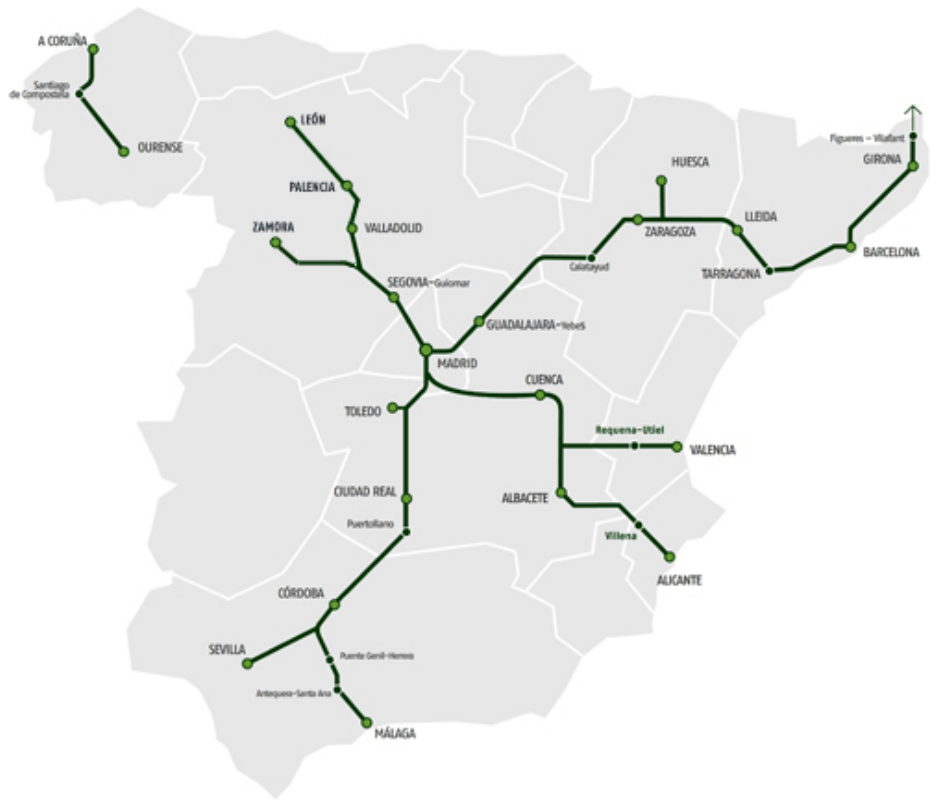

Fuente: ADIF 2017.

La construcción de esta red de alta velocidad ha sido objeto de razonadas críticas por el elevado volumen de inversiones requeridas (más de 45.000 M€ a fecha de hoy, según ADIF), impactos ambientales, cuestionable rentabilidad económica, costes de oportunidad en relación a otras posibles inversiones y las prioridades establecidas en su ejecución en pro de las conexiones radiales con la capital de España (Albalate y Bel, 2011; Betancor y Llobet, 2015; De Rus, 2015, entre otros). Desde otra perspectiva, y es también la que adoptan los sectores económicos vinculados a la construcción, se pone el acento en el efecto que tal volumen de inversión tiene en el PIB, empleo y retorno fiscal (Herce y Sosvilla-Rivero, 2002), o su papel como "herramienta" de la política económica, así como la reducción de los tiempos de viaje y que el ferrocarril haya entrado en competencia con la carretera y el avión ${ }^{16}$. En relación con la articulación y cohesión territorial, otro de los grandes objetivos de los planes

15 http://www.adifaltavelocidad.es/es_ES/infraestructuras/lineas_de_alta_velocidad/ lineas_de_alta_velocidad.shtml

16 La cuota del ferrocarril con respecto al avión es del 90,1\% en la relación Madrid-Sevilla, 84,6\% MadridMálaga, 77,1\% en la de Madrid-Alicante y 58,6\% Madrid-Barcelona. RENFE. Informe Anual 2013: 75 
de infraestructuras, el argumento de mayor peso es la reducción de los tiempos de viaje entre las poblaciones servidas, pero también se produce un "efecto túnel" por su incapacidad para contribuir a la generación de actividad económica entre los nodos y el territorio por el que discurren las vías (Hernández, 2011: 8).

Tras la apertura en 2013 de la conexión con la frontera francesa por Figueras y la relación Albacete-Alicante, los principales avances en los últimos años se han realizado en el cuadrante noroeste con la puesta en servicio en 2015 de los tramos Medina-Zamora de la LAV Madrid-Galicia y Valladolid-Palencia-León ${ }^{17}$, en el primer caso avanzando en la conexión con Galicia por el denominado acceso sur de anteriores planes, y en el segundo hacia Asturias a través de la Variante de Pajares (49,7 kilómetros, de los cuales 24,60 km en los túneles de igual denominación); tales actuaciones son fuertemente reclamadas desde los respectivos territorios y han contado con un alto apoyo político desde el Gobierno Central, pero son de aún más dudosa rentabilidad que la de las líneas ya en servicio. En cambio, se han pospuesto las inversiones en el Corredor Mediterráneo, la $Y$ vasca y la conexión con Portugal. El Corredor Mediterráneo, cuyo potencial económico y poblacional está fuera de toda duda, forma parte de los principales ejes desde el PTF1987 y en algunos planes (PIT2000 y PITVI2012) figura como realizado entre Castellón y Vandellós; pero lo cierto es que es un corredor de doble vía electrificada en ancho ibérico y tráfico mixto, con un estrangulamiento entre Vandellós y Tarragona por donde se circula aún en vía única, si bien está prevista que entre en servicio en ancho ibérico próximamente; el Corredor Mediterráneo es objeto de una fuerte reivindicación empresarial y política, por parte del lobby FERRMED tras su constitución en 2004 y los gobiernos autonómicos del litoral mediterráneo, con más fuerza en Valencia y menos en Andalucía. El retraso en la ejecución de este corredor ha sido explicado (Libourel, 2016) como parte del enfrentamiento del Gobierno Central y las regiones mediterráneas, especialmente Cataluña, o por la escasa sensibilidad del primero por una articulación territorial que no conecta con la capital de España, a pesar de su potencial económico y su contribución a la ordenación territorial. La Y vasca es la prioridad del Gobierno Vasco, así como su conexión a la red francesa (Vitoria-Dax), que ya figuraba en la primera relación de proyectos transeuropeos de $1994^{18}$, pero no ha sido ejecutada aún. Portugal, por su parte, anunció en 2008 que posponía la ejecución de la línea de alta velocidad, que es lo que le da sentido como línea transeuropea, si bien en España se mantienen obras entre Cáceres y Badajoz.

En el balance de la alta velocidad y en relación con los costes de oportunidad, es necesario destacar que el sistema ferroviario español mantiene $5.118,5 \mathrm{~km}$ en vía única y sin elec-

17 También en 2015 se han finalizado las obras de remodelación de la línea Sevilla-Cádiz, de características similares a las del Eje Atlántico en Galicia, no incluida en la figura $\mathrm{n}^{\circ} 8$.

18 En el Consejo Europeo de Essen (1994) se incorporaron dos proyectos prioritarios en territorio español: Madrid-Barcelona-Perpiñan-Montpellier y Madrid-Vitoria-Dax. En 2006 se firmó un convenio entre la Administración General del Estado y el Gobierno Vasco para avanzar en su ejecución, en el que el segundo participaría con la correspondiente minoración de las aportaciones del cupo vasco a la AGE: "Convenio entre la Administración General del Estado, la Administración General de la Comunidad Autónoma del País Vasco y el Administrador de la Infraestructura Ferroviaria para la construcción de la nueva red ferroviaria en el País Vasco" http://www. adifaltavelocidad.es/es_ES/infraestructuras/doc/Convenio_Ministerio_Gobierno_Vasco.pdf Aún así, no se dispone actualmente de fecha de puesta en servicio y es uno de los objetos de negociación entre el Gobierno de Madrid y el de Vitoria en la legislatura iniciada en octubre de 2016. 
trificar (OFE, 2014, p. 20): en torno al 45\% de la red en ancho ibérico ${ }^{19}$. En las valoraciones que se vienen realizando sobre las inversiones ferroviarias en España, se pone menos el acento en el hecho de que se mantenga una buena parte de la red convencional en vía única no electrificada y trazado decimonónico, con resultado de bajas prestaciones, escasa utilización y sin rentabilidad económica, de forma que ADIF apunta con ambigüedad a la insostenibilidad de mantenerla toda en servicio ${ }^{20}$. Este acusado y persistente desequilibrio entre una parte del sistema y otro contribuye hacer más insistente la reclamación de la alta velocidad como única alternativa, se considera, para la mejora de los servicios ferroviarios en aquellos territorios que no disponen de tal infraestructura.

Por otra parte, la implantación de la alta velocidad en ancho estándar, coexistiendo con el ancho convencional de la red española, hace más patente el desequilibrio y segregación entre ambas redes, por lo que difícilmente puede hablarse de un único sistema ferroviario. Decisión soslayada por el coste económico y las dificultades técnicas y operativas que supone, el PEIT2005 plantea la necesidad de proceder a la migración de toda la red hacia el ancho estándar, planteamiento que mantiene el PITVI2012. En estos momentos las traviesas polivalentes están instaladas en $4.620 \mathrm{~km}$ de la RFIG (Red Ferroviaria de Interés General) ${ }^{21}$, todas ellas montadas en ancho ibérico, pero sin fecha horizonte para proceder al cambio, pues para ello será preciso contar con una red continua y coherente dotada de tales traviesas y la disponibilidad del material de transporte adecuado, y que requerirá de una logística minuciosamente planificada para proceder a la migración. Mientras tanto, los cambiadores de ancho y el tercer carril permiten una integración parcial de ambos sistemas y la utilización de una misma línea por distintos vehículos ferroviarios de pasajeros y mercancías. Esta larga transitoriedad, sin fecha horizonte prevista, lleva a recurrir a planes intermedios, costosos, de no fácil operativa e insatisfactorios para los usuarios ${ }^{22}$.

\section{CONCLUSIONES}

A partir de la constatación de la consolidación de la planificación como instrumento de intervención de las Administraciones en sus respectivos ámbitos competenciales, con la que abríamos este trabajo, nuestro objetivo ha sido analizar la trayectoria seguida por los planes sobre infraestructura ferroviaria en España en los últimos 30 años para conocer sus contenidos, la coherencia de cada uno de los planes, el grado de continuidad o ruptura entre unos y otros. En suma, la deriva que han seguido y en qué medida la planificación ha orientado la acción pública.

19 Hay importantes discrepancias entre esta cifra y la recogida en el PITVI2012: 29-30.

20 "ADIF ha puesto en marcha diversas medidas tendentes a la consecución de la sostenibilidad económica... No obstante, la sostenibilidad económica dependerá del modo que se afronten los factores que hemos identificados como más críticos: Más de 1500 kilómetros de baja ocupación e ineficientes medioambientalmente, ..." (a la que siguen otros factores). ADIF, 2014: 27.

21 https://sede.adif.gob.es/es_ES/ocio_y_cultura/fichas_informativas/ficha_informativa_00037.shtml

22 Véase como ejemplo la propuesta presentada por el Ministerio de Fomento para el Corredor Mediterráneo: Proyecto de implantación del ancho UIC en el Corredor Mediterráneo de Murcia a Castellbisbal: http://www. fomento.gob.es/NR/rdonlyres/109f0858-a15e-4f8c-b1d7-77c7f37fa9d8/114420/121218_Presentacion_proyecto_ implantacion_UIC_Corr.pdf 
En este periodo se han sucedido hasta cuatro documentos de planificación general (plan director, plan estratégico) de las infraestructuras del transporte que son competencias de la Administración General del Estado, precedido por un plan específico ferroviario. Cada cambio en la dirección política del País ha venido acompañado de un nuevo plan, de modo que el periodo de vigencia de cada uno de ellos ha oscilado entre los cinco y los ocho años. Otra consecuencia de la sustitución de un plan por otro en tan corto espacio de tiempo es que ningún plan ha sido sometido a un proceso de evaluación y/o revisión de sus principios, objetivos o propuestas. Y esto, como también apuntábamos en la introducción, cuando el periodo de planificación y ejecución de una infraestructura de transporte se prolonga por decenios.

Por ello, a pesar de su aparente ruptura con el plan anterior y la proclamación de nuevos principios y objetivos, cada plan ha sido esencialmente continuista con las propuestas del precedente, pero al mismo tiempo ha tratado de superar al anterior hasta el punto que el actualmente en vigor ha llevado su propuesta de extensión de la alta velocidad en España, donde toda reclamación queda recogida, con independencia de cualquier otro criterio. Ello responde, en mi opinión, al vértigo que provoca el agravio comparativo territorial, como parte del vértigo al debate territorial per se. El plan no opta, no establece prioridades y pospone la decisión a una programación de facto, de carácter político, técnico y/o financiero.

Distintos intereses, reales o supuestos, coinciden para que los planes se hayan aprobado en tales términos de máximos. Están los intereses de los distintos gobiernos autonómicos reclamando unas inversiones en sus territorios similares a las que se han ejecutado o se prevén ejecutar en otros; una vez que fue olvidada la pretensión del PDI1993 de que otras Administraciones territoriales participasen en la financiación de las nuevas líneas de alta velocidad, es una reclamación a coste económico cero para quienes las exigen, a la vez que se le presume réditos políticos. Por otra parte, están los intereses de los sectores empresariales beneficiados por las inversiones en infraestructuras, sectores situados en los primeros puestos del ranking de las empresas españolas y de alta capacidad de influenciar en las decisiones de la Administración. Asimismo, la opinión pública, regulada su presencia en los procesos de planificación pero no suficientemente articulada aún, puede manifestar posiciones diferentes, con algunos grupos a favor de una revisión de estas propuestas expansivas, pero otra parte convencida de los beneficios que podría reportarle la construcción de nueva infraestructuras. De Flaubert (Madame Bovary) a Berlanga (Bienvenido Mr. Marshall) ha sido expresada de forma magistral esa simbiosis entre intereses políticos y búsqueda del favor local a través de las inversiones en infraestructuras. La Administración Central, por su parte, justifica sus propuestas en argumentos considerados de peso: el papel de la planificación en el equilibrio y la cohesión territorial, y el de las inversiones que conlleva como herramienta de la política económica.

Finalmente, la cuestión que debe contestarse es la utilidad de la planificación en la acción de gobierno, hasta qué punto la dirige u orienta. En nuestra opinión, los planes de infraestructuras del transporte en España se sustentan en un elevado savoir faire, un alto know how técnico, realizan un diagnóstico preciso de la situación de partida, y han ido consolidando principios y objetivos acerca de la eficiencia del sistema tanto en términos económicos, como sociales y ambientales, el fortalecimiento de la cohesión social y territorial, el impulso al desarrollo económico, o la coordinación y cooperación entre las Administraciones, en buena medida impelidos por los principios emanados de los documentos estratégicos euro- 
peos o por sus Directivas sobre seguridad en el transporte, interoperabilidad, intermodalidad, o eficiencia energética. Aun cuando estemos lejos de alcanzar los objetivos expresados en esos o similares términos, tales principios se han ido asentando gracias a los planteamientos recogidos en los documentos de planificación.

Pero al mismo tiempo los planes, en particular los más recientes, tienen un elevado componente político, que distorsiona en sus propuestas finales buena parte de la bondad de la planificación. El plan hace una propuesta homogeneizadora y de máximos, donde ningún territorio queda excluido y todos los territorios reciben un tratamiento equitativo. Con ello, se pone a prueba los mismos principios de la planificación: la asignación más eficiente de los recursos disponibles, en términos económicos y de sostenibilidad.

\section{REFERENCIAS}

ALBALATE, D. y BEL, G. (2011): “Cuando la economía no importa: Auge y esplendor de la Alta Velocidad en España”, Revista de Economía Aplicada, 55 (XIX), 171-190.

APARICIO MOURELO, A. (2010): "El confuso papel del ferrocarril en el sistema de transporte español", Revista de Obras Públicas, n 3514, 7-20.

BENABENT, M. (2014): Introducción a la teoría de la planificación territorial. Sevilla, Universidad de Sevilla.

BETANCOR, O. y LLOBET, G. (2015) "Contabilidad financiera y social de la Alta Velocidad en España”,en FEDEA, Estudios sobre la Economía Española. Documentos de Trabajo 2015/8. Disponible en http://www.fedea.net/

DE RUS, G. (2015) "La política de infraestructuras en España. Una reforma pendiente", en FEDEA Policy Papers (FPP), 2015/8, disponible en http://documentos.fedea.net/pubs/ fpp/2015/10/FPP2015-08.pdf

FERRROPEDIA. El Plan de Transporte Ferroviario de 1987. Disponible en: http://ferropedia.es/wiki/Plan_de_Transporte_Ferroviario_\%281987\%29

HERCE, J.A. y SOSVILLA-RIVERO, S. (2002): "Efectos económicos de las inversiones ferroviarias en España 1991-2007”, FEDEA. Documento de trabajo 25/2002. Disponible en http://documentos.fedea.net/pubs/dt/2002/dt-2002-25.pdf

GÓMEZ MENDOZA, A. (1989): Ferrocarril, industria y mercado en la modernización de España. Madrid, Espasa-Calpe.

HERNÁNDEZ, A. (2011): "Los efectos territoriales de las infraestructuras. La inversión en redes de alta velocidad ferroviaria”, en FEDEA. Colección Estudios Económicos 05-2011. Disponible en http://documentos.fedea.net/pubs/ee/2011/05-2011.pdf

IZQUIERDO, R., MENÉNDEZ, J.M., ZARAGOZA, A., MONZÓN, A. y ECHEVARRI, A. (1999): "Evolución del transporte terrestre", Revista de Obras Públicas, n 3388, 38-50

LIBOUREL, E. (2016): El Corredor Mediterráneo. Desencuentro político y territorial. Valencia. Universitat de Valencia.

LÓPEZ CORRAL, A. (2000); "El Presupuesto del Ministerio de Fomento y el Plan de Infraestructuras 2000-2007", Revista de Obras Públicas, n 3403, 7-16.

LÓPEZ CORRAL, A. (2004): "Estado de ejecución del Plan de Infraestructuras del Transporte 2000-2007 y Presupuesto para 2004 del Grupo Fomento", Revista de Obras Públicas, $\mathrm{n}^{\mathrm{o}} 3443,7-17$. 
MORENO FERNÁNDEZ, J. (1999): “El ancho de vía: un parámetro controvertido”, en MUÑOZ RUBIO, M., SANZ FERNÁNDEZ, J. y VIDAL OLIVARES, J. (Eds.) Siglo y medio del ferrocarril en España 1848-1998. Economía, industria y sociedad. Madrid, Fundación de Ferrocarriles Españoles, 723-738.

MUÑOZ RUBIO, M. (1994): Desarrollo económico y ferrocarril entre 1941 y 1982. De la hegemonía a la marginalidad. (Documento de trabajo). Madrid, Fundación Empresa Pública.

ROJAS URTASUN, F. y HERRERA CHAMORRO, M.A. (2008): "Presupuesto del Grupo Fomento en 2008 y evolución 2000-2008”. Instituto de Estudios Fiscales, 50/2008, 119 150. Disponible en http://www.ief.es/documentos/recursos/publicaciones/revistas/presu_ gasto_publico/50_PresupuestoGrupoFomento.pdf

SERRANO MARTÍNEZ, J.M., GARCÍA MARÍN, R. y GIL GUIRADO, S. (2010): “La política de transporte ferroviario en España. Los corredores de alta velocidad: sus potenciales y limitaciones" Scripta Nova. Revista Electrónica de Geografía y Ciencias Sociales. [En línea]. Barcelona: Universidad de Barcelona, 1 de agosto de 2010, vol. XIV, $\mathrm{n}^{\circ}$ 331 (20). <http://www.ub.es/geocrit/sn/sn-331/sn-331-20.htm>. [ISSN: 1138-9788.

VILLARONTE MARTÍNEZ, J.A. (1999): “Configuración de la red nacional ferroviaria actual”, Revista de Obras Públicas, n 3388, 161-170.

\section{DOCUMENTACIÓN}

ADIF. Memoria Económica 2014. Dispoible en:

https://sede.adif.gob.es/ca_ES/compromisos/doc/Memoriaeconomica14_1_165.pdf

ADIF 2017. Disponible en http://www.adifaltavelocidad.es/es_ES/infraestructuras/lineas_ de_alta_velocidad/lineas_de_alta_velocidad.shtml, consultado 14 de enero de 2017

CONGRESO DE LOS DIPUTADOS (2004). Pleno, $n^{\circ} 2$. Debate de Investidura del Presidente Rodríguez Zapatero. Disponible en http://www.congreso.es/public_oficiales/L8/ CONG/DS/PL/PL_002.PDF

CONGRESO DE LOS DIPUTADOS (2012). Comisiones: Fomento, $\mathrm{n}^{\circ}$ 166. Comparecencia de la Ministra de Fomento para informar sobre el Plan de infraestructuras, transporte y vivienda 2012-2020, presentado en el Consejo de Ministros el día 3 de agosto de 2012. Disponible en http://www.congreso.es/portal/page/portal/Congreso/PopUpCGI?CMD=VERDOC\&CONF=BRSPUB . $\mathrm{cnf} \& \mathrm{~B} A \mathrm{SE}=\mathrm{PU} 10 \& \mathrm{PIECE}=\mathrm{PU} 10 \& \mathrm{DOCS}=1-1 \& \mathrm{FMT}=\mathrm{PUWTXDTS}$. fmt\&OPDEF $=Y \& Q U E R Y=\% 28 D \% 29 . P U B L .+\% 26+\% 28 C O N G$

CONVENIO entre la Administración General del Estado, la Administración General de la Comunidad Autónoma del País Vasco y el Administrador de la Infraestructura Ferroviaria para la construcción de la nueva red ferroviaria en el País Vasco, 24 de abril de 2006. Disponible en http://www.adifaltavelocidad.es/es_ES/infraestructuras/doc/Convenio_Ministerio_Gobierno_Vasco.pdf

LIBRO BLANCO (2011). Hoja de ruta hacia un espacio único europeo del transporte: por una política del transporte competitivo y sostenible. Bruselas 28.3.2011 COM(2011) 144 final. 
MINISTERIO DE FOMENTO (2012) Proyecto de implantación del ancho UIC en el Corredor Mediterráneo. De Murcia a Castellbisbal. Disponible en http://www.fomento.gob. es/NR/rdonlyres/109f0858-a15e-4f8c-b1d7-77c7f37fa9d8/114420/121218_Presentacion_proyecto_implantacion_UIC_Corr.pdf

MINISTERIO DE FOMENTO (2014). Anuario Estadístico 2014. Capitulo 12. Transporte Ferroviario. Disponible en 2014http://www.fomento.gob.es/MFOM/LANG_CASTELLANO/ATENCION_CIUDADANO/INFORMACION_ESTADISTICA/EstadisticaSintesis/Anuario/2014/TablasAnuario2014.htm

OBSERVATORIO DEL FERROCARRIL EN ESPAÑA (OFE2014). Informe 2014. Documento de trabajo, diciembre de 2015. Disponible en http://www.fomento.gob.es/ferrocarriles/OBSFERRO/Informe_OFE2014.pdf

PLAN DIRECTOR DE INFRAESTRUCTURAS, 1993-2007 (1994) (PDI1993), Madrid, Ministerio de Obras Públicas, Transportes y Medio Ambiente (MOPTMA)

PLAN DE INFRAESTRUCTURAS FERROVIARIAS 1995-2000 (1995), (PIF1995), Madrid, Ministerio de Obras Públicas, Transportes y Medio Ambiente (MOPTMA), 2 vols

PLAN ESTRATÉGICO DE INFRAESTRUCTURAS Y TRANSPORTE 2005-2020 (PEIT2005). Madrid: Ministerio de Fomento. Disponible en http://www.fomento.es/ MFOM/LANG_CASTELLANO/_ESPECIALES/PEIT/http://peit.cedex.es

PLAN DE INFRAESTRUCTURAS, TRANSPORTE Y VIVIENDA. PITVI (2012-2024) (2015). Madrid, Ministerio de Fomento. Disponible en http://www.fomento.gob.es/NR/ rdonlyres/E35B8D33-F3B6-4695-9012-C22229966FA0/130944/PITVI20122024.pdf

PLAN GALICIA (2003) Referencia del Consejo de Ministros de 24 de enero 2003. Disponible en http://www.lamoncloa.gob.es/consejodeministros/referencias/Paginas/2003/ c2401030.aspx\#comisióninterministerial

RENFE. Informe Anual, 2013. Disponible en http://www.renfe.com/docs/Informe_ anual_2013.pdf

\section{NORMATIVA}

LEY 39/2003, de 17 de noviembre, del sector ferroviario. Disponible en https://boe.es/buscar/act.php?id=BOE-A-2003-20978

DECISIÓN 1692/EC del Parlamento Europeo y el Consejo de 23 de julio de 1996. Disponible en http://eur-lex.europa.eu/LexUriServ/LexUriServ.do?uri=CELEX:31996D1692:ES:HTML

DIRECTIVA 96/48/CE, relativa a la interoperabilidad del sistema ferroviario transeuropeo de Alta Velocidad. Disponible en http://eur-lex.europa.eu/legal-content/ES/TXT/HTML/ ?uri=URISERV:124095\& from $=$ ES

DIRECTIVA 2001/16/CE relativa a la interoperabilidad del sistema ferroviario convencional. Disponible en https://www.boe.es/doue/2001/110/L00001-00027.pdf

DIRECTIVA 2012/34/UE DEL PARLAMENTO EUROPEO Y DEL CONSEJO de 21 de noviembre de 2012 por la que se establece un Espacio Ferroviario Europeo Único. Disponible en http://www.boe.es/doue/2012/343/L00032-00077.pdf 
REAL DECRETO 1434/2010 de 5 de noviembre sobre interoperabilidad del sistema ferroviario de la Red Ferroviaria de interés general. Disponible en https://www.boe.es/boe/ dias/2010/11/06/pdfs/BOE-A-2010-17037.pd

REGLAMENTO (UE) N $\mathrm{N}^{\mathrm{0}}$ 1315/2013 del Parlamento Europeo y del Consejo, de 11 de diciembre de 2013, sobre las orientaciones de la Unión para el desarrollo de la Red Transeuropea de Transporte, y por el que se deroga la Decisión n ${ }^{0}$ 661/2010/UE. Disponible en https://www.boe.es/doue/2013/348/L00001-00128.pdf

RESOLUCIÓN de la Secretaria de Estado de Infraestructura, Transporte y Vivienda por la que se formula el documento final del Plan de Infraestructura, Transporte y Vivienda, 15 de mayo de 2015. Disponible en http:/www.fomento.gob.es/NR/rdonlyres/9C7046DDBEF6-4DD4-B6E4-4E3ADAF6DB60/130924/ResolucionSEPITVI.pdf 
